\title{
O IMPACTO DE JEAN PIAGET COMO REFERÊNCIA EM EDUCAÇÃO PARA PROFESSORES DE SÃO JOSÉ DO RIO PRETO
}

Felipe Colombelli Pacca ${ }^{1}$, Stephanie Lee Basile Barboza Caseiro², Cristiano Marcos Coope ${ }^{2}$, Raul Aragão Martins ${ }^{2}$

${ }^{1}$ Faculdade Ceres - FACERES, Núcleo de avaliação e Núcleo de Formação e Apoio Docente, São José do Rio Preto, SP.

${ }^{2}$ Universidade Estadual Paulista - UNESP.E-mail: felipepacca@gmail.com

\section{RESUMO}

Na realidade comum da escola e ambientes educacionais, o nome de Jean Piaget é bastante lembrado e utilizado. Há de se discutir, inclusive, que Jean Piaget traduz, atualmente, o que é educação para os professores de Ensino Infantil e primeiros ciclos do Ensino Fundamental. $O$ objetivo deste estudo foi o de demonstrar que Jean Piaget é o autor mais reconhecido como educador para os professores de São José do Rio Preto, SP. A metodologia foi realizada a partir da análise de frequência de respostas, categorização e análise de categorias de um instrumento aplicado para 992 professores de 66 escolas da cidade. Os resultados apontam que mais de $77 \%$ de todos os entrevistados indicaram o nome de Piaget como um estudioso de educação e que a categoria mais lembrada pelos docentes foi o construtivismo (média de 51,9\% de ocorrências). Concluímos que a produção de Jean Piaget tem impacto determinante na prática profissional do professor e que esses resultados não determinam o entendimento ou desentendimento dos conceitos apresentados por Jean Piaget sobre o processo de desenvolvimento humano.

Palavras-chave: Jean Piaget, Construtivismo, Impacto.

\section{THE IMPACT OF JEAN PIAGET AS REFERENCE IN EDUCATION FOR TEACHERS OF SÃO JOSÉ DO RIO} PRETO

\begin{abstract}
The common reality of school and educational settings presents the name of Jean Piaget as quite remembered and used. There to discuss, including Jean Piaget translates, currently, what is education for Childhood Education teachers and first cycle of primary education. The aim of this study was to demonstrate that Jean Piaget is the most recognized author and educator for teachers of São José do Rio Preto, SP. The methodology consisted of analysis of frequency responses, categorization and analysis of categories of an instrument applied to 992 teachers from 66 schools in the city. The results show that over $77 \%$ of all respondents indicated the name of Piaget as a scholar education and the category most remembered by teachers was constructivism (average of $51.9 \%$ of occurrences). We conclude that the production of Jean Piaget has a decisive impact on the professional practice of the teacher and that these results do not determine the understanding or misunderstanding of the concepts presented by Jean Piaget on the human development process.
\end{abstract}

Keywords: Jean Piaget, Constructivism, Impact 


\section{INTRODUÇÃO}

No processo de mediação da aprendizagem escolar, o professor tem papel determinante. No entanto, professor não nasce preparado. Ele é fruto de processos de formação teórica e prática, que condensam, normalmente, toda a experiência, leituras, discussões e problemas desses profissionais.

De acordo com o educador, pedagogo e filósofo brasileiro Paulo Freire:

Ninguém começa a ser educador numa certa terça-feira às quatro horas da tarde. Ninguém nasce educador ou marcado para ser educador. A gente se faz educador, a gente se forma como educador, permanentemente, na prática e na reflexão sobre a prática. (FREIRE, 1991, p.32)

Cabe, então, ao educador, ampliar e compreender a existência de valores, práticas, teorias, integrações, atitudes, conteúdos sobre educação e sua aplicação. Porém, muito A despeito da ocorrência de propostas educacionais realizadas pelos profissionais sem o embasamento de concepções teóricas esclarecidas, todo professor tem em alguém um modelo do que considera a tradução de educação.

Diversas são as possibilidades teóricas, autores e educadores para o professor embasar sua prática, como, por exemplo, o construtivismo, tendo como representante Jean William Fritz Piaget (1994, 1970a). Há também a teoria histórico-crítico, cujo expoente é o educador Paulo Reglus Neves Freire (1991), e o behaviorismo, de Burrhus Frederic Skinner (1972). Muitas outras correntes teóricas tem em algum autor seu condutor principal. Dessa maneira, defender um autor específico diz muito sobre a prática, sobre as crenças e sobre as visões de educação de um professor.

No caso de Piaget, por exemplo, Osti (2009, p. 110) aponta que

Os estudos de Piaget procuram explicar como se desenvolve o raciocínio lógico, enfocando a gênese do conhecimento. Piaget teve como principal objetivo estudar o sujeito epistêmico, buscou compreender os processos de pensamento presentes desde a infância até a idade adulta. Suas pesquisas procuraram responder a seguinte questão: como se passa de um estado de menor conhecimento para outro de maior conhecimento? Piaget considera que o homem herda um organismo, ou seja, possui uma máquina biológica que irá amadurecer em contato com o meio ambiente, servindo como base sobre a qual todas as aprendizagens serão construídas. Portanto, o homem herda estruturas orgânicas que são chamadas de invariantes funcionais - como o sistema digestivo, respiratório, circulatório, dentre outros, e estruturas mentais, que compreendem a possibilidade de construção do conhecimento (OSTI, 2009, p. 110)

Neste contexto, para Piaget o indivíduo é o agente de seu próprio conhecimento. É o próprio indivíduo que "constrói" seu conhecimento autonomamente. Em relação ao desenvolvimento dessa autonomia, Piaget (1994 e 1970b), o comportamento do indivíduo é considerado de acordo com a moralidade e ética. Essa ideia, por si só, direciona a prática, as crenças e valores dos professores que adotam o autor como ícone em educação. Outra perspectiva interessante sobre o trabalho de Piaget é apresentada por De La Taille (1999), na discussão de limites enquanto objeto de estudo de educação.

No entanto, Freitas (2002, p. 13) aponta que existe, no entanto, precariedade na compreensão das ideias de Piaget no meio educacional, o que sinaliza dificuldades com a prática docente e aponta uma discrepância entre crença, teoria e prática na realidade do professor. Pacca (2013, p. 
Independente da prática, das discussões e dos pressupostos teóricos, Piaget é um nome presente na realidade do professor brasileiro, em especial àqueles de educação infantil e dos primeiros ciclos do Ensino Fundamental. Questiona-se aqui o impacto do nome Jean Piaget para os profissionais de educação enquanto colaborador do processo de educação, formação e prática docente?

Em pesquisa realizada em 2012, Pacca (2013) investigou 992 professores de 66 escolas de São José do Rio Preto, SP, e identificou nomes de educadores que contribuíram para a educação de acordo com os entrevistados. O objetivo deste trabalho é apresentar o impacto do nome Jean Piaget enquanto referências para educação em São José do Rio Preto

\section{METODOLOGIA}

Os procedimentos metodológicos deste estudo e seus resultados são parte da coleta de dados e dissertação de mestrado de Pacca (2013) e são apresentados em duas etapas: inicialmente são descritos os procedimentos adotados na elaboração, como a escolha do material utilizado e a definição de critérios e formatação adotados; a seguir, são apresentados os procedimentos de aplicação do instrumento, a definição do local e dos participantes, os procedimentos de análise de dados e, por fim, as considerações éticas da pesquisa.

Optou-se pela utilização de uma pesquisa por levantamento, com a aplicação de instrumento de verificação da aceitação ou rejeição das citações de autoria de Skinner sobre educação, na perspectiva do Behaviorismo Radical. O pesquisador incluiu no instrumento, no entanto, uma questão aberta na qual solicitava aos participantes que citassem estudiosos que tiveram contribuição para a educação, cujos resultados aqui apresentados não foram foco principal da discussão de resultados de seu trabalho.

O processo de elaboração do instrumento seguiu, de acordo com Cozby (2003, p. 156), os cuidados necessários para a formulação, considerando a simplicidade, as questões ambíguas, as questões tendenciosas e também o cuidado com as formulações negativas. A elaboração do instrumento seguiu o seguinte procedimento: definição da obra; delimitação das questões; envio para juízes; seleção das questões para instrumento; formatação do questionário; envio para juízes especialistas.

Não é objeto de interesse neste estudo a descrição do desenvolvimento das questões sobre behaviorismo radical (proposta principal do trabalho de Pacca, 2013), porém, é necessário apresentar a informação de, para traçar o perfil dos participantes, foram incluídas no instrumento quatro questões de múltipla escolha e uma questão aberta. As questões de múltipla escolha versavam sobre a idade dos participantes, a escolaridade deles (sempre com graduação como mínimo), sobre o tipo de graduação (pública ou privada) e também sobre o tempo de experiência profissional de cada participante. A questão aberta solicitava aos participantes que indicassem algum estudioso de educação. $O$ objetivo foi o de avaliar quais teorias educacionais estão sendo mais lembradas pelos professores.

Os procedimentos de coleta foram padronizados, desde o contato inicial com cada uma das escolas, até a aplicação do instrumento. As escolas participantes foram escolhidas pela sua posição geográfica, buscando o equilíbrio entre escolas municipais, escolas privadas e escolas conveniadas de acordo com listagem disponibilizada pela Secretaria Municipal de Educação de São José do Rio Preto/SP. A escolha foi determinada a partir de orientações estatísticas, porém aconteceram sem um método definido. Em caso de replicação, aconselhamos que a escolha das escolas seja realizada por sorteio, dividindo-se a área da pesquisa em quadrantes, garantindo assim uma amostra estratificada.

Participaram da pesquisa 66 escolas, sendo 35 delas escolas municipais, 25 escolas conveniadas e 6 escolas privadas. É necessário informar que as escolas conveniadas são escolas que recebem incentivo financeiro da Prefeitura Municipal de São José do Rio Preto e oferecem 
serviços gratuitos à comunidade. As escolas ainda se subdividiam em Escolas de Educação Infantil, Escolas de Ensino Fundamental I e Escolas de Educação Infantil e Ensino Fundamental I.

Em relação aos participantes, participaram deste estudo 992 professores, formados em pedagogia, das redes pública e privada de Ensino de São José do Rio Preto, atuantes em 66 escolas da cidade. Os números relativos ao total de professores com o perfil desejado foram obtidos junto à Secretaria de Educação de São José do Rio Preto, atingindo uma população de 2500 profissionais, atuantes em 223 escolas na cidade.

Os procedimentos de coleta foram determinados e seguidos pela equipe de coleta. Em suma, os professores participantes eram reunidos durante o horário de reunião, divididos em grupo (parte essencial para os resultados da pesquisa) e instruídos a responder os questionários. Amostras de conveniência para divisão dos grupos não foram cogitadas. Separados em grupos, os participantes recebiam e assinavam o termo de consentimento livre e esclarecido, quando então indicavam sua identidade e consentimento. $O$ procedimento de coleta aconteceu entre 14 de maio e 26 de junho de 2012.

$\mathrm{Na}$ análise dos participantes, as categorias estabelecidas foram determinadas após a análise da média de resultados e desvio padrão. No caso da variável idade, quatro categorias foram determinadas a partir das datas de nascimento informadas. A variável pós-graduação foi resumida, dado o número de mestres e doutores participantes não ser estatisticamente representativo. A variável formação foi mantida com os dois critérios apontados. Por fim, a variável tempo de serviço em sala de aula foi agrupada também em categorias determinadas a partir da data informada.

Uma das questões solicitava aos participantes que indicassem nomes de estudiosos que eles conheciam cujas teorias contribuíram para a educação. Sem a indicação de quantidade, houve variação de indicações desde zero até 16 indicações. Em média, os participantes indicaram quatro estudiosos. Essas indicações resultaram em mais de 120 nomes. Para analisar essa questão, foi necessário categorizar os nomes indicados. Essa categorização foi realizada, primeiramente, pelo pesquisador, que, a partir de pesquisas bibliográficas de cada um dos nomes citados, determinou e inclui os nomes em categorias. As categorias, com cada um dos nomes citados, foram então enviadas para quatro juízes (dois psicólogos e dois pedagogos) que avaliaram a classificação, avalizando os nomes (ou não) em cada uma das categorias. Em caso de não aceitação, os juízes deveriam então sugerir uma categoria existente para a mudança do nome citado, ou mesmo indicar uma nova categoria. As correções e sugestões foram então novamente avaliadas pelo pesquisador, que determinou então a classificação final, utilizando, como critério de mudança de categoria, as indicações de dois juízes, no mínimo. No caso de empates, o critério para a escolha da categoria para cada nome era a pesquisa inicial do pesquisador. Após a reavaliação, as categorias determinadas para análise foram: a) Autoajuda; b) Behaviorismo; c) Cognitivismo; d) Construtivismo; e) Escola nova; f) Filosofia; g) Histórico-Crítica; h) Linguística e Literatura; i) Política educacional; j) Psicanálise; k) Sociologia, e; I) Outros autores. A partir dessas categorias, as frequências de respostas foram analisadas e descritas nos resultados.

Para a realização desta pesquisa, foram solicitadas autorizações da Delegacia Regional de Ensino de São José do Rio Preto, da Secretaria Municipal de Educação de São José do Rio Preto e de cada uma das escolas participantes, na figura da direção ou coordenação. Todos os participantes da pesquisa receberam o termo de consentimento livre e esclarecido, contendo informações sobre a pesquisa e contato do pesquisador. Esta pesquisa foi submetida e aprovada pelo Comitê de Ética da Faculdade de Filosofia e Ciências (UNESP/Marília) sob o parecer no 0374/2011. 


\section{RESULTADOS}

O tempo de serviço em sala de aula, em média, foi de 12 a 15 anos. A maioria dos participantes, 861 , teve sua formação superior em instituições privadas (86,8\%). Além disso, 43,4\% (431 participantes) possuíam pós-graduação, considerando especialização, mestrado e doutorado. Apenas 6 homens participaram deste estudo e, dessa maneira, não houve divisão e análises por gênero, pois há predominância do sexo feminino entre professores de Educação Infantil e Ensino Fundamental I. Os participantes apresentaram idade média de 37 anos, com mínimo de 21 e máximo de 68 anos, e um desvio padrão de 9,69. Em relação ao tempo de serviço em sala de aula, a média foi de 12,04 anos, em que o mínimo atingiu 0,7 anos (pouco mais de oito meses) e o máximo de 48 anos em sala de aula, com desvio padrão de 9,02.

A maior parte dos participantes $(86,8 \%)$ realizou seus estudos de graduação em universidades ou faculdades privadas. Apenas 10,2\% deles realizou a graduação em universidades públicas. Os 3\% restantes não informaram os dados sobre formação. Em relação ao nível de instrução dos participantes, 53,4\% eram graduados, 43,4\% eram pós-graduados e 3,2\% dos participantes não informaram o nível de instrução. No entanto, é preciso informar que, entre os participantes que fizeram pós-graduação, nenhum doutor e apenas seis mestres participaram da pesquisa. Como a ocorrência de doutores e mestres não foi estatisticamente relevante, optou-se por incorporar as categorias em uma única, denominada "pós-graduação".

Em relação aos estudiosos indicados pelos participantes, de acordo com a categorização determinada, apresentamos a Tabela 1, que demonstra a frequência de citações por categoria. Essas frequências são apresentadas em 16 linhas, pois o valor de indicações de estudiosos variou de zero a 16 nomes em um mesmo instrumento respondido. A intenção dessa análise é conseguir visualizar a categoria que teve frequência de maior destaque e, a partir dessa visualização, discutir tais resultados.

Tabela 01. Frequência de citações por categorias

\begin{tabular}{cccccccccccccc}
\hline & $\mathbf{A}$ & $\mathbf{B}$ & $\mathbf{C}$ & $\mathbf{D}$ & $\mathbf{E}$ & $\mathbf{F}$ & $\mathbf{G}$ & $\mathbf{H}$ & $\mathbf{I}$ & $\mathbf{J}$ & $\mathbf{K}$ & $\mathbf{L}$ & $\begin{array}{c}\text { Não } \\
\text { Informados }\end{array}$ \\
$\mathbf{1}$ & $\mathbf{6}$ & 2 & 2 & $\mathbf{7 9 1}$ & 1 & 0 & 128 & 0 & 0 & 2 & 0 & 6 & 54 \\
$\mathbf{2}$ & 13 & 48 & 8 & 127 & 14 & 2 & $\mathbf{6 2 5}$ & 0 & 0 & 6 & 0 & 6 & 143 \\
$\mathbf{3}$ & 20 & 0 & 16 & 303 & 17 & 8 & $\mathbf{3 3 2}$ & 2 & 2 & 13 & 0 & 20 & 259 \\
$\mathbf{4}$ & 12 & 0 & 39 & $\mathbf{3 3 9}$ & 40 & 11 & 44 & 3 & 7 & 15 & 1 & 33 & 448 \\
$\mathbf{5}$ & 8 & 0 & 43 & $\mathbf{2 1 2}$ & 4 & 16 & 13 & 4 & 9 & 17 & 1 & 23 & 642 \\
$\mathbf{6}$ & 9 & 1 & 30 & $\mathbf{9 8}$ & 3 & 8 & 11 & 4 & 7 & 14 & 1 & 16 & 790 \\
$\mathbf{7}$ & 9 & 0 & 18 & $\mathbf{4 6}$ & 2 & 6 & 10 & 2 & 5 & 5 & 2 & 20 & 867 \\
$\mathbf{8}$ & 2 & 1 & 9 & $\mathbf{1 6}$ & 0 & 4 & 5 & 0 & 3 & 3 & 2 & 11 & 936 \\
$\mathbf{9}$ & 1 & 1 & $\mathbf{6}$ & $\mathbf{6}$ & 1 & 2 & 2 & 0 & 5 & 2 & 0 & 4 & 962 \\
$\mathbf{1 0}$ & 0 & 0 & 4 & $\mathbf{5}$ & 0 & 1 & 0 & 0 & 4 & 0 & 0 & 1 & 977 \\
$\mathbf{1 1}$ & 0 & 0 & $\mathbf{3}$ & 2 & 0 & 0 & 1 & 0 & $\mathbf{3}$ & 0 & 0 & $\mathbf{3}$ & 980 \\
$\mathbf{1 2}$ & 0 & 0 & 1 & 0 & 0 & 1 & 1 & 0 & 0 & 0 & 0 & $\mathbf{3}$ & 986 \\
$\mathbf{1 3}$ & 0 & 0 & 0 & 0 & 0 & $\mathbf{1}$ & $\mathbf{1}$ & 0 & 0 & 0 & 0 & 0 & 990 \\
$\mathbf{1 4}$ & 0 & 0 & 0 & $\mathbf{1}$ & 0 & 0 & $\mathbf{1}$ & 0 & 0 & 0 & 0 & 0 & 990 \\
$\mathbf{1 5}$ & 0 & 0 & 0 & 0 & $\mathbf{1}$ & 0 & 0 & 0 & 0 & 0 & 0 & 0 & 991 \\
$\mathbf{1 6}$ & 0 & 0 & 0 & 0 & 0 & $\mathbf{1}$ & 0 & 0 & 0 & 0 & 0 & 0 & 991 \\
\hline
\end{tabular}

As categorias referentes à Tabela 1 seguem a ordem apresentada na metodologia deste trabalho: a) Autoajuda; b) Behaviorismo; c) Cognitivismo; d) Construtivismo; e) Escola nova; f) Filosofia; g) Histórico-Crítica; h) Linguística e Literatura; i) Política educacional; j) Psicanálise; k) Sociologia, e; I) Outros autores. 
A partir das frequências apresentadas, é possível observar que a categoria D Construtivismo - é a mais lembrada pelos professores. Nas cinco primeiras indicações de estudiosos, as alternativas D e G - Histórico-Crítica - são as que mais se destacam. A média de frequência da categoria $D$ foi de $51,9 \%$, a maior entre todas as frequências. A média foi calculada a partir do total das frequências de cada categoria, pelo número total de categorias. Os dados não informados não foram computados no cálculo de porcentagem da média. Os resultados apresentados demonstram que $85,4 \%$ dos nomes indicados estão concentrados em apenas duas categorias: D - construtivismo e G - Histórico-Crítico.

O nome de Jean Piaget foi indicado como referência de educador para 764 participantes $(77,01 \%)$.

\section{DISCUSSÃO}

A formação docente é um processo individual se pensarmos que cada professor deve buscar suas próprias ferramentas para a construção de sua prática embasada em teoria. Ela também é um processo coletivo, visto que todo professor precisa de auxílio e novas experiências, discussões e informações para dar continuidade em seu desenvolvimento. Seja pela capacitação por cursos, pela busca individual, pela pressão do ambiente educacional, pelas experiências únicas com alunos específicos, o professor busca uma identidade, busca uma fundamentação.

No caso da realidade em São José do Rio Preto, os resultados demonstram que essa identidade buscada pelos professores tem seu embasamento em Jean Piaget e no Construtivismo, o que sugere um direcionamento dos processos de educação focados no sujeito aprendiz e não no sujeito docente.

Questiona-se, a partir dos resultados, o porquê dos professores indicarem tanto o nome de Jean Piaget em detrimento de outras correntes. Uma das prováveis respostas seja talvez a necessidade, em uma realidade cada vez mais dinâmica e populosa, de tornar a escola um local de práticas voltadas para o desenvolvimento individual, não coletivo, mas em grupo, de nossas crianças. Mais do que uma teoria sem aplicação, é provável que o impacto de Jean Piaget seja o elemento norteador das práticas pedagógicas do futuro.

\section{CONCLUSÃO}

A partir dos dados apresentados, é possível observar que Jean Piaget é um dos ícones da educação da região, sendo uma das bases teóricas da prática dos professores. Essa realidade demonstra que o nome de Piaget tem impacto significativo para os professores de São José do Rio Preto, SP.

\section{REFERÊNCIAS}

COZBY, Paul C. Métodos de pesquisa em ciências do comportamento. São Paulo: Atlas, 2003.

DE LA TAILLE, Yves. Limites: três dimensões educacionais. São Paulo: Ática, 1999.

FREIRE, Paulo. A educação na cidade. São Paulo: Cortez Editora, 1991. 144p.

FREITAS, Lia Beatriz de Lucca. Autonomia moral na obra de Jean Piaget: a complexidade do conceito e sua importância para a educação. Educar, Curitiba, n. 19, p. 11-22, 2002.

OSTI, Andréia. Concepções sobre desenvolvimento e aprendizagem segundo a psicogêncese piagetiana. Revista de Educação, Valinhos, v. XII, n. 13, p. 109-118, 2009. 
PACCA, Felipe Colombelli. Investigação de conhecimento teórico: aceitação/rejeição ao behaviorismo radical entre professores. 2013, Marília. Dissertação (Mestrado em Educação). Universidade Estadual Paulista, Faculdade de Filosofia e Ciências.

PIAGET, Jean. O juízo moral na criança. São Paulo: Summus, 1994.

PIAGET, Jean. O nascimento da inteligência na criança. Rio de Janeiro: Zahar, 1970a.

PIAGET, Jean. Psicologia e pedagogia. Rio de Janeiro: Forense, 1970b.

SKINNER, Burrhus F. Tecnologia do Ensino. São Paulo, Herder, Ed. Da Universidade de São Paulo, $1968 / 1972$ 